\title{
Effect of different filters on the extraction of norbixin from Bixa orellana for synthetic fiber dyeing and development of a post-dyeing process for removal of the unfixed dye
}

\author{
Marcel Jefferson Gonçalves ${ }^{\mathrm{a}, b^{*}}$, Cynthia Baptista Pereira ${ }^{\mathrm{b}}$, Nathália Meyer Manske ${ }^{\mathrm{b}}$, Crisleine Regina \\ Hillesheim ${ }^{\mathrm{c}}$, Amábile Colla Prando ${ }^{\mathrm{b}}$, Sávio Leandro Bertolic ${ }^{\mathrm{c}}$, Rita de Cássia Siqueira Curto Valle ${ }^{\mathrm{e}}$, Ivonete \\ Oliveira Barcellos ${ }^{\mathrm{d}}$ and Lorena Benathar Ballod Tavares ${ }^{\mathrm{a}}$
}

\begin{abstract}
${ }^{a}$ Regional University of Blumenau (FURB), Postgraduate Program in Environmental Engineering, Blumenau, SC, Brazil.
${ }^{b}$ Regional University of Blumenau (FURB), Chemical Engineering Department, Blumenau, SC, Brazil.

${ }^{c}$ Regional University of Blumenau (FURB), Postgraduate Program in Chemical Engineering, Blumenau, SC, Brazil.

${ }^{d}$ Regional University of Blumenau (FURB), Chemistry Department, Blumenau, SC, Brazil.

${ }^{e}$ Federal University of Santa Catarina (UFSC), Postgraduate Program in Textile Engineering, Blumenau, SC, Brazil.
\end{abstract}

ARTICLE INFO

Keywords:

Environment,

natural dye,

polyester.

\begin{abstract}
The aim of this study was to compare the efficiency of three types of filters for the extraction of the annatto dye from Bixa orellana for polyester dyeing. In addition, post-dyeing washing processes were proposed to improve the wash and rubbing fastness. In the extraction was not possible to state that a specific filter had a higher yield, with values between $11.4 \%$ to $13.3 \%$ and also there was no significant difference in the results for the exhaustion (average of $87.4 \%$ ) and $\mathrm{K} / \mathrm{S}$ values (1.68 to 2.24 ). Results showed the polypropylene filter was the most suitable and can be reused. The post-dyeing washing processes with detergent improved the fastness increasing the color transfer score from 1.5 to 3 . An acceptable color difference between the dyed fabric samples before and after washing was observed. Results indicate that the post-dyeing washing process improves the quality of dyed fabrics to levels acceptable for industrial application.
\end{abstract}

\section{Introduction}

Annatto, also known as urucum, is one of the oldest natural dyes and its extraction from Bixa orellana seeds and application in the dyeing of fabrics has recently been gaining interest from researchers. According to Mercadante et al (1997), the concentration of the dye generally found in the coating of $B$. orellana seeds is $4.5 \%$ by mass and is comprised of carotenoids, consisting of 70 to $80 \%$ bixin and norbixin (Preston and Rickard, 1980; Singh and Bharati, 2014). The main motivation for studies on these dyes is their high biodegradability, low toxicity, high availability, and potential antioxidant and antimicrobial properties, but their stability in textile substrates needs to be optimized (Bueno et al., 2020; Gonçalves et al., 2020; Nathan et al., 2019; Shahid-Ul-Islam et al., 2016).

The textile industry has a high economic and social importance and a great diversity of processes are used to manufacture colored fabrics, ensuring income to millions of people (Criado et al., 2020). However, they are associated with a high consumption of water and consequently generate large amounts of effluent (Chicatto et al., 2018a; Petris et al., 2019; Rainert et al., 2017). In some stages of the textile industry processes, notably dyeing, aggressive chemicals, such as synthetic dyes, are used, which generate colored and potentially toxic effluents resulting in adverse effects on the environment if not properly treated (Rainert et al., 2021). Textile dyes also can act as mutagenic and carcinogenic agents (Lellis et al., 2019).

Therefore, the use of natural dyes can lead to the generation of less toxic effluents (Bunfueang et al., 2019). The study of the application of natural dyes for various types of textile fibers as a substitute for synthetic dyes has been growing and this approach is becoming increasingly necessary for the development of strategies to achieve sustainability. Natural dyes have a lesser impact on the environment, but studies are required to optimize their application and achieve viability for industrial use.

Some publications show that fabrics dyed with the natural dye annatto show unsatisfactory results in wash fastness tests, reinforcing the need for research aimed at solving this problem (Bunfueang et al, 2019; Chicatto et al., 2018c, 2018b; Mahreni et al., 2019; Nathan et al., 2019; Samanta, 2020; Shahid et al., 2013). In order to expand our knowledge on this subject, the extraction of the natural dye annatto (norbixin), for the dyeing of polyester fabric, was investigated using three different types of filters. The insertion of a washing process after the dyeing, to assist in the removal of the nonfixed dye, was also studied. The polypropylene (PP) filter showed the best performance and was thus used to perform six repetitions of the tests and evaluate the possibility of reusing the same filter in subsequent filtrations.

\section{Methodology}

The natural dye annatto was obtained from the extraction of seeds of the plant Bixa orellana, in alkaline solution $(5 \% \mathrm{NaOH})$, for 60 min at $70{ }^{\circ} \mathrm{C}$, followed by washing with water and sieving to eliminate the seeds, in this way the extracted dye is expected to be majorly in the norbixin form (Bechtold and Mussak, 2009). To provide data which appears to be absent in the literature, three types of filters (cotton, paper and PP) were evaluated for the removal of the finest solids, since these can interfere negatively in the dyeing. For the dye purification, acid precipitation was then performed at $\mathrm{pH} 4.5$ with vacuum filtration through the filter paper (qualitative) followed by drying to constant mass. The extraction yield was calculated based on the initial mass of the seeds and final annatto mass obtained in the extractions, after drying. All tests were performed in duplicate. 
For the characterization of the dye, analysis using a UV-VIS spectrophotometer (UV-1650pc SHIMADZU) was performed, with scanning between 300 and $700 \mathrm{~nm}$, in order to verify that the maximum absorption bands are those characteristic of the annatto dye $(453 \mathrm{~nm}, 470 \mathrm{~nm}$ and 482 $\mathrm{nm})$. The dye was diluted in alkaline solution until the measurements were in the absorbance range of 0.3 to 0.8 (Bechtold and Mussak, 2009).

The norbixin content of the annatto dye was determined applying an adapted version of a previously described methodology (Bareth et al, 2002; Da Costa and Chaves, 2005; Lucarini et al., 2017). In this procedure, a solution of $20 \mathrm{mg}$ $\mathrm{L}^{-1}$ of the annatto dye powder (previously extracted from the seeds, purified and dried) was prepared in $2.5 \%$ potassium hydroxide and absorbance readings were then taken at wavelengths of $453 \mathrm{~nm}, 470 \mathrm{~nm}$ and $482 \mathrm{~nm}$ (region of the spectrum corresponding to the maximum absorption peaks of norbixin in potassium hydroxide solution). Dilutions were performed as necessary, to obtain absorbance values between 0.3 and 0.8 . To calculate the norbixin content the Lambert-Beer law can be used, which relates the concentrations of solutions containing color to the transmittance of light passing through the sample, as proposed by Da Costa and Chaves (2005) and seen in Equation 1. A molar absorptivity coefficient of 2870 was used, thus assuming that the compound is in the form of norbixin.

$$
C=\frac{A b s * 1000}{E_{1 c m}^{1 \%} * d_{c}}
$$

Where: $\mathrm{C}=$ norbixin concentration in $\mathrm{mg} \mathrm{L}^{-1}$ (the value of 1000 in the equation transforms the original concentration from grams to milligrams); $A b s=$ absorbance read at the wavelength; $\mathrm{E} 1 \mathrm{~cm} \%=$ norbixin absorptivity coefficient (2870); and dc = optical path of the cell $(1.0 \mathrm{~cm})$.

Samples (10 g) of $100 \%$ polyester Jersey-type fabrics, with a weight of 277 $\mathrm{g} / \mathrm{m}^{2}$, were purged with a bath ratio (mass of fabric per volume of bath = $\mathrm{g}_{\text {fabric }} / \mathrm{mL}_{\text {bath }}$ ) of $1: 10$, to remove oils and impurities. The procedure performed consists of purging at $80^{\circ} \mathrm{C}$ for $30 \mathrm{~min}$, followed by neutralization with acetic acid $\left(0.2 \mathrm{~g} \mathrm{~L}^{-1}\right)$ and two more washes at room temperature, as schematically shown in Figure 1. During the purging, $1.5 \mathrm{~g} \mathrm{~L}^{-1}$ of non-ionic detergent and $2 \mathrm{~g}$ $\mathrm{L}^{-1}$ of sodium carbonate were added, as proposed in the literature with modifications to adhere to the procedure currently used by the textile plants in the region Bueno et al. (2020).

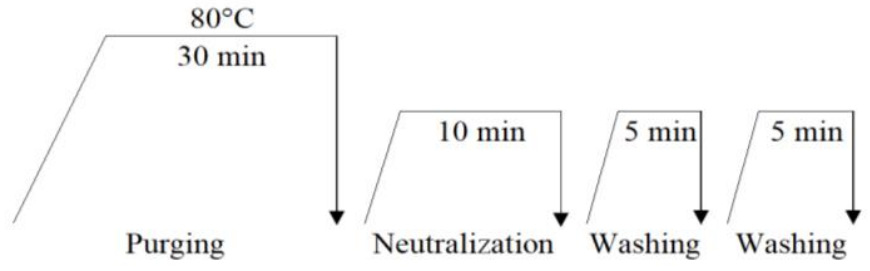

Figure 1. Graph of the purging performed on the fabrics

After purging, the fabrics were dried, thermoset and stored for later use in the dyeing process.

Dyeing was performed on the purged fabrics, using $5 \mathrm{~g}$ samples of fabric, a bath ratio (mass of fabric per volume of bath $=g_{\text {fabric }} / \mathrm{mL}_{\text {bath }}$ ) of $1: 10$ and dye concentration of $1.5 \%(\mathrm{~m} / \mathrm{m})$. The $\mathrm{pH}$ was maintained at 4.5 and the temperature at $130{ }^{\circ} \mathrm{C}$ for $45 \mathrm{~min}$, followed by rinsing for $10 \mathrm{~min}$ with only water at $80{ }^{\circ} \mathrm{C}$ (Bueno et al., 2020). After dyeing the samples were dried and subsequently the quality of the dye fixation was evaluated by the fastness test.

The determination of the amount of dye adsorbed on the fabric (exhaustion percentage) was carried out by measuring the absorbance of the liquid samples on a UV-VIS spectrophotometer (UV-1650pc SHIMADZU) at the wavelength of maximum absorption of the dyes. To calculate the percent exhaustion (E\%), the absorbance readings of a "blank" sample, that is, a sample of the initial bath without fabric (initial sample), which was then subjected to the dyeing temperature and time, and a sample of the bath residue after the dyeing of the fabrics (final sample) were considered, according to Equation 2 (Mittersteiner et al., 2017).

The reading of the blank samples was required due to the instability of the annatto dye under conditions of high temperature and low $\mathrm{pH}$ (Bueno et al., 2020).

$$
E \%=\frac{A b s_{\text {initial }}-A b s_{\text {final }}}{A b s_{\text {initial }}} * 100
$$

Where: Absinitial is the absorbance of the blank bath subjected to the same temperature and time conditions as the dyeing bath and Absfinal is the absorbance of the bath after the dyeing of the fabric samples.

The color intensity $(\mathrm{K} / \mathrm{S})$ for the dyed fabrics was measured based on readings taken using a remission spectrophotometer (Minolta-Mathis). The chromaticity coordinates and $\mathrm{K} / \mathrm{S}$ (at $490 \mathrm{~nm}$ ) values are obtained directly by the equipment.

The fastness observed in the washing and rubbing tests demonstrates the quality of the dye fixation in the dyed fabrics. The wash fastness tests, conducted at a temperature of $40^{\circ} \mathrm{C}$, were performed according to ISO $105-\mathrm{CO} 6$ (ISO, 2010) and the rubbing fastness tests according to ISO 105-X12 (ISO, 2016). Measurements to determine the color difference $(\Delta E)$ values for the dyed fabrics and the control fabrics were performed on a remission spectrophotometer (Minolta-Mathis).

The post-dyeing washing process aims to remove the dye not fixed to the polyester fiber during dyeing, thus improving the color fastness during the rubbing and washing of the dyed fabrics. Two detergent formulations were proposed and applied after the dyeing process, aiming to improve the wash fastness (which showed low values for the dyed samples). The first formulation (F1) involved the use of the detergent Sera Wash C-CIV (2 $\left.\mathrm{g} \mathrm{L}^{-1}\right)$ for $15 \mathrm{~min}$ at 95으 $\mathrm{C}$ and for the second (F2) a reductive alkaline bath with $2 \mathrm{~g} \mathrm{~L}^{-1}$ of sodium metabisulfite and $1 \mathrm{~g} \mathrm{~L}^{-1}$ of $\mathrm{NaOH}$ was used for $15 \mathrm{~min}$ at $80^{\circ} \mathrm{C}$. After each washing procedure, the samples were dried and the fastness tests and color measurements were repeated.

\section{Results And Discussion}

The UV/Vis spectrometry carried out at between 300 and $700 \mathrm{~nm}$ showed two maximum absorption peaks $(\lambda=454 \mathrm{~nm}$ and $\lambda=482 \mathrm{~nm})$ for the extracted dye values similar to those reported by Da Costa and Chaves (2005). The highest absorption peak found and considered for the color readings of the baths was $454 \mathrm{~nm}$, which, according to Bechtold and Mussak (2009), is a value typical for the annatto dye.

The extraction performed in alkaline solution increased the norbixin content in the filtered dye, with concentrations ranging from 0.468 to $0.570 \mathrm{mg} \mathrm{L}^{-1}$ depending on the wavelength used in the reading, as shown in Table 1.

Table 1. Average norbixin content obtained in the extractions, with readings performed at different wavelengths.

\begin{tabular}{|c|c|c|}
\hline $\begin{array}{c}\text { Wavelength } \\
\lambda(\mathrm{nm})\end{array}$ & $\begin{array}{c}\text { Norbixin } \\
\left(\mathrm{mg} \mathrm{L}^{-1}\right)\end{array}$ & $\begin{array}{c}\text { Standard } \\
\text { Deviation }\end{array}$ \\
\hline 453 & 0.570 & \pm 0.073 \\
\hline 470 & 0.519 & \pm 0.071 \\
\hline 482 & 0.468 & \pm 0.064 \\
\hline
\end{tabular}

Lucarini et al. (2017) performed the extraction of norbixin with various solvents and alkaline aqueous mixtures and obtained values ranging from 0.35 to 2.26 $\mathrm{mg} \mathrm{L}^{-1}$, a range similar to that reported by Tocchini and Mercadante (2001).

Table 2 and Figure 2 show the results for the average yields of the extractions performed with different types of filters and the respective percentage exhaustion of the extracted dyes, along with the color intensity of the dyed fabrics (K/S). 
Table 2. Extraction yields for each filter, exhaustion and $\mathrm{K} / \mathrm{S}$ value of the dyes

\begin{tabular}{|c|c|c|c|c|c|c|}
\hline \multirow[b]{2}{*}{ Filter } & \multicolumn{2}{|c|}{ Extraction yield } & \multicolumn{2}{|c|}{ Exhaustion dyeing } & \multicolumn{2}{|c|}{$\mathrm{K} / \mathrm{S}$ of dyed fabrics } \\
\hline & $\%$ & $\begin{array}{l}\text { Standard } \\
\text { Deviation }\end{array}$ & $\%$ & $\begin{array}{l}\text { Standard } \\
\text { Deviation }\end{array}$ & $\mathrm{K} / \mathrm{S}$ & $\begin{array}{l}\text { Standard } \\
\text { Deviation }\end{array}$ \\
\hline Cotton & 11.4 & \pm 0.42 & 87.8 & \pm 2.41 & 2.24 & \pm 0.08 \\
\hline Paper & 13.3 & \pm 1.83 & 86.9 & \pm 1.41 & 1.68 & \pm 0.47 \\
\hline PP & 11.4 & \pm 0.92 & 87.4 & \pm 2.91 & 2.06 & \pm 0.16 \\
\hline
\end{tabular}

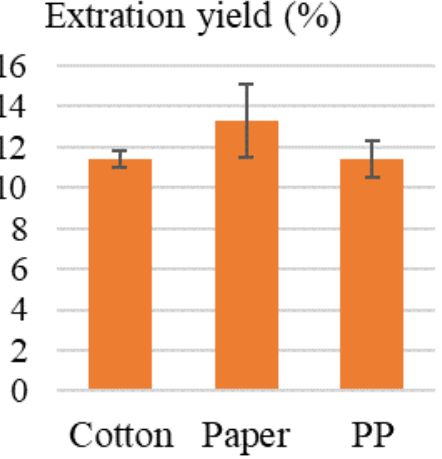

(a)

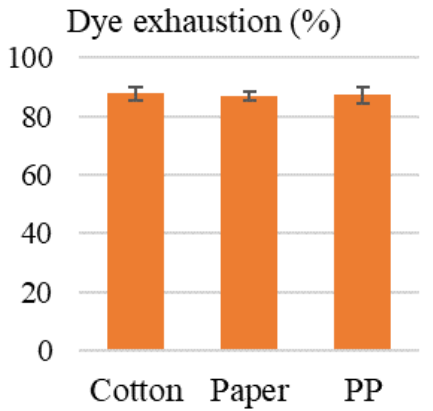

(b)
Color intensity $(\mathrm{K} / \mathrm{S})$

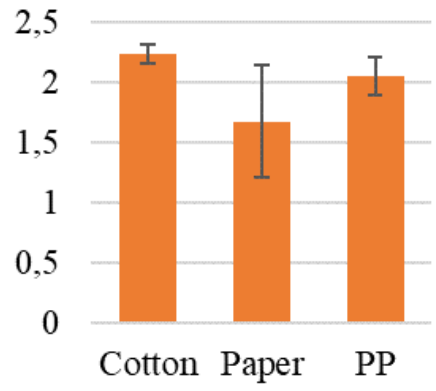

(c)

Figure 2. Yield of dye extraction performed with different filters (a), dye exhaustion in the dyeing process (b) and color intensity of the dyed fabrics (c)

The type of filter had no significant influence on the variables studied. The objective of the filter is to concentrate the dye and, in this case, eliminate impurities that can affect the exhaustion of the dyeing and the color and fastness of the dyed fabric. The results indicate that all filters studied had similar behavior. In an experiment conducted by Da Costa and Chaves (2005), the extraction yield was $6.2 \%$ with ethanol solvent, while Chan-Bacab et al. (2015) achieved $14,2 \%$ yield, with microwave assisted extraction method, using hot distilled water $\left(100^{\circ} \mathrm{C}\right)$ for $60 \mathrm{~min}$ and followed by extraction with paper filter. Similar value was obtained in this study, which reached $13.3 \%$ for the paper filter. Solvent extractions tend to be more selective than aqueous extractions, which can reduce the amount of material extracted and consequently the extraction yield. The filter type does not seem to have an influence on this aspect. The choice of the type of solvent (polar or non-polar) will depend on the type of subsequent application and will influence the yield of the process and the products extracted. In the case of application in dyeings, the most used method is aqueous extraction.

In general, the average exhaustion values were very similar. The $\mathrm{K} / \mathrm{S}$ values are similar to those reported in the literature by Bueno et al. (2020) with K/S 4.96 to $2.5 \%$ of dye and Zaman et al. (2018) with 1.45 to $1.0 \%$ of dye. On analyzing the data for the standard deviation (DesvPad) of the extraction yields and the $\mathrm{K} / \mathrm{S}$ values, there is a large oscillation in the results, which can be attributed to the particularities of the variable behavior of plant products such as annatto.

The Figures 3 and 4 show the average results for the quality tests performed on the dyed fabrics, i.e., rubbing fastness (dry and wet) and wash fastness. The transfer fastness scores for the cotton (CO) and polyester (PES) control fabrics range from 1 (worst) to 5 (best).

Rubbing fastness

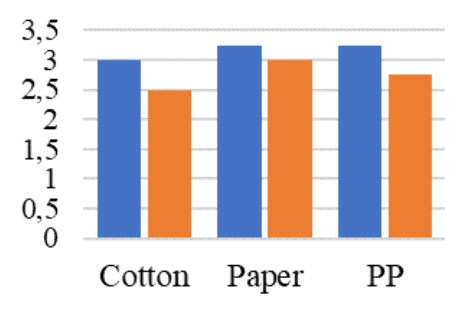

Dry $\square$ Wet

Figure 3. Results of rubbing fastness and wash fastness

\section{Wash fastness}

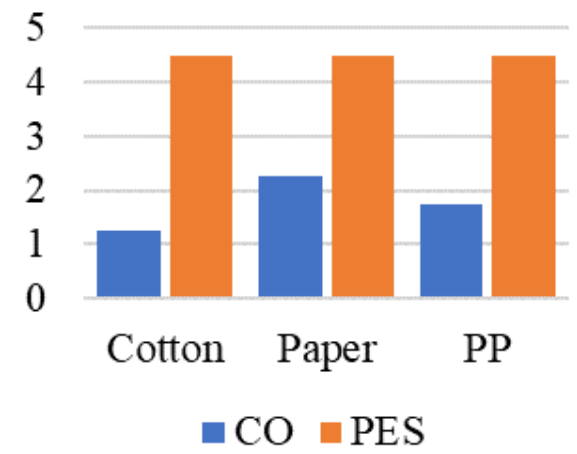

Figure 4. Results of rubbing fastness tests of dyed

According to the Brazilian Association of Technical Standards (ABNT) the ideal score for dyeing with acceptable fastness is above 3.5. Some of the scores obtained were below this value and, thus, in further experiments a washing post-dyeing process was added.

In the color transfer to the cotton control fabric the best performance was obtained with filter paper (2.5), followed by PP (2.0) and lastly cotton (1.5). In a study with dyeing using annatto the authors (Bunfueang et al., 2019; ChanBacab et al., 2015) also found low fastness values, with a transfer score of 2.5 for the cotton control fabric. There was no statistical difference between the other fastness scores. On analyzing the results for the extraction yield, exhaustion, $\mathrm{K} / \mathrm{S}$ and color fastness and also considering that the use of the PP screen in the annatto filtration has the advantage of the possibility of reuse, this one was chosen as the best filter option and used for further studies. To verify the feasibility of reusing the PP filter in successive extractions of the dye, six more extractions were performed using the same filter.

Table 3 shows the results for the extraction yield, the percentage exhaustion of the dyes, the $\mathrm{K} / \mathrm{S}$ value measured for the dyed fabric, and the transfer fastness test scores for the cotton (CO) and polyester (PES) control fabrics, for the six extraction repetitions using the same filter. Analysis of variance (ANOVA) tests were performed for all groups of values and none showed a significant difference at the $95 \%$ confidence level, confirming the possibility of reusing the PP filter for this number of repetitions. 
Table 3. Yield values of the extractions reusing the PP filter and results of the dyeing and quality tests of the dyed fabric

\begin{tabular}{cccccc}
\hline & $\begin{array}{c}\text { Extraction } \\
\text { yield }\end{array}$ & $\begin{array}{c}\text { Exhaustion in } \\
\text { dyeing }\end{array}$ & $\begin{array}{c}\text { Coloristic } \\
\text { Intensity }\end{array}$ & \multicolumn{2}{c}{$\begin{array}{c}\text { Transfer fastness } \\
\text { scores }\end{array}$} \\
\hline Sample & $\%$ & $\%$ & K/S & CO & PES \\
\hline 1 & 10.7 & 88.3 & 2.67 & 1.5 & 4.5 \\
2 & 9.6 & 86.6 & 2.50 & 2 & 4.5 \\
3 & 11.9 & 86.8 & 1.91 & 2 & 4.5 \\
4 & 10.5 & 88.1 & 2.63 & 1,5 & 4.5 \\
5 & 8.9 & 84.8 & 2.97 & 2 & 4.5 \\
6 & 13.0 & 89.6 & 1.98 & 1.5 & 4.5 \\
\hline
\end{tabular}

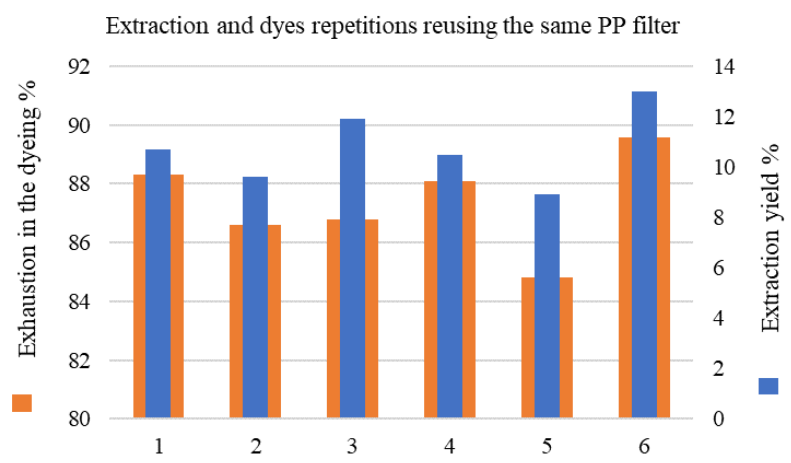

Figure 5. Yield of the dye extractions and percentage of exhaustion in the dyeings

The percentage of exhaustion ranged from 84.8 to $89.6 \%$ for the dyed fabrics and showed no direct relationship with the extraction yield, according to Figure 5. The author Bueno et al. (2020) noted that annatto exhaustion was approximately $84 \%$ for polyester fabrics, a value very close to that observed in this study. Importantly, this value is also similar for synthetic dispersed dyes, varying from around 83.4 to $98.5 \%$ (Hao et al., 2019). An inversely proportional trend between the wash fastness scores and the $\mathrm{K} / \mathrm{S}$ values for the dyed fabrics can be observed in Figure 6 . A possible explanation for this is that the higher the $\mathrm{K} / \mathrm{S}$ value the greater the amount of dye deposited on the dyed fabric will be and a portion of this will subsequently be released during the wash fastness test, reducing the respective stain score of the control fabric.

Repetitions reusing the same PP filter

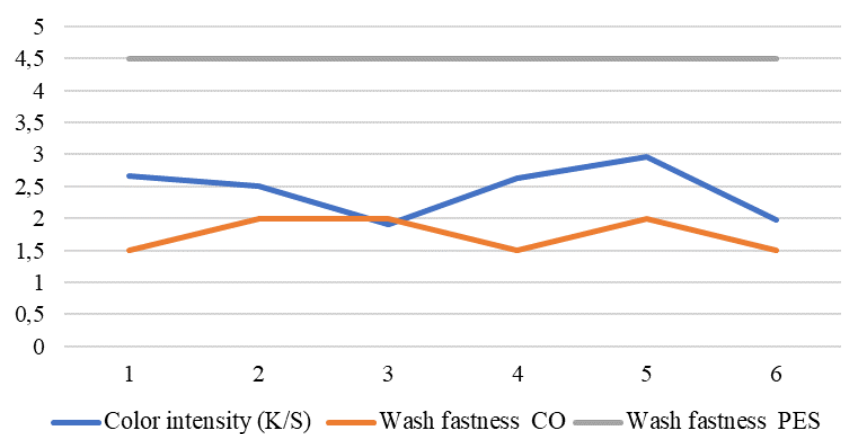

Figure 6. Color intensity and wash fastness scores of dyed fabrics

The maximum value of 2.97 for the $\mathrm{K} / \mathrm{S}$ remained within the expected range for this concentration of dye, as also reported by Bueno et al. (2020) and Nakpathom et al. (2019). The fastness scores for the cotton control fabric ranged from 1.5 to 2.0, indicating low fastness for the dyed fabric, values very close to those reported by Zaman et al. (2018). This indicates that not all of the dye present in the fiber is effectively adhered to the fabric, requiring some additional process (washing) for its removal. In the case of the fastness of the polyester control fabric, the value of 4.5 indicates good quality.

The samples chosen to perform the post-dyeing washing process were those that obtained the worst score for wash fastness and higher $\mathrm{K} / \mathrm{S}$ values, that is, samples 1 and 4 (Table 3). Figure 7 shows the average results obtained in the fastness tests for formulations F1 and F2, with the corresponding transfer scores for the cotton (a) and polyester (b) control fabrics.

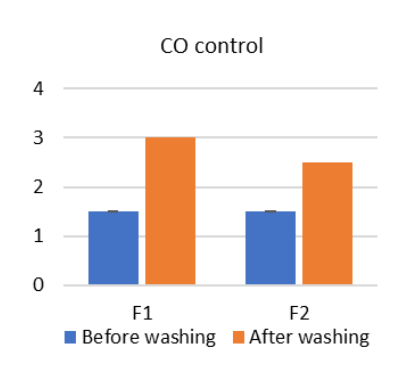

(a)

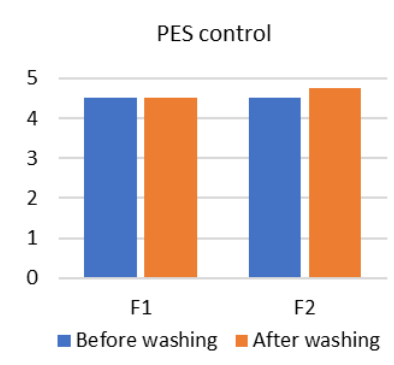

(b)

Figure 7. Comparison of wash fastness results before and after the post-dyeing 


\section{washing process}

The wash fastness score for the cotton control fabric, which was previously 1.5, increased to 3.0 for both F1 samples while for F2 it increased to 2.5. For the polyester control fabrics, since the scores were initially good (4.5) there was little improvement for sample 4 (F2), with the maximum score being 5.0.
In general, when colored fabrics are subjected to a washing process, some color loss occurs (Agnhage et al., 2016). To investigate this, the colors of the fabric measured before and after the post-dyeing washing process were compared, for the two formulations tested, and Table 4 shows the values obtained for the color difference.

Table 4. Measurement of color difference of dyed fabrics after washing

\begin{tabular}{cccc}
\hline Sample & Formulation & $\Delta \mathrm{E}$ & Visual Perception \\
\hline 1 & F1 & 0.23 & Very Small \\
4 & F1 & 1.66 & Slightly distinguishable \\
1 & F2 & 1.33 & Small
\end{tabular}

For F1, the color difference after washing was very small or slightly distinguishable with the naked eye, while for F2 it ranged from small to easily distinguishable (Buchelt and Wagenführ, 2012; Chiarello et al., 2020). The visual perception classification followed the recommendations of DIN 6174 (2007), that is, below 1.5 the visual difference perceived to the human eye is irrelevant to the quality of the dyed fabrics and the fabric therefore adheres to industrial manufacturing standards. This clearance standard for the color difference $(\Delta E)$ between dyed samples can vary according to the requirement of each customer and can reach 0.5. For F1, even the highest value (1.66) was very close to the value associated with 'not perceived by the naked eye'. However, it is noteworthy that with the insertion of the post-dyeing washing process, the color standard is the final processed and washed sample itself. Therefore, the $\Delta \mathrm{E}$ values were not presented with the objective of approving/rejecting the color difference after washing, but as a parameter to demonstrate the small color difference after washing and verify the feasibility of this process, since the wash fastness scores were elevated to values very close to those considered acceptable for most textile applications.

\section{Conclusions}

The extraction yields and K/S values for the dyed fabrics showed some oscillation but were not significantly influenced by the type of filter used in the extraction. The same was observed for the percentage of exhaustion, which presented even less oscillation ( 84.8 to $89.6 \%$ ). A difference was found in the case of fastness (washing and rubbing tests), for which more favorable results were obtained for the paper and PP filters. Six successive extractions were performed with the same PP filter and similar results in terms of yield, dyeing and fastness were obtained, demonstrating its potential for reuse in the filtration process.

According to the results obtained, it can be concluded that by submitting the dyed fabrics to washing using the F1 formulation, the dye that did not adhere to the polyester fiber is removed, improving the results of the fastness tests, with a significant improvement in the color transfer to the cotton control fabric. For F2, the improvement in fastness was not so pronounced. Therefore, it is possible to affirm that the F1 post-dyeing washing procedure demonstrated good performance, increasing the possibility for the use of the natural dye extracted from the annatto, since the fabrics submitted to this process presented fastness and color difference which adhere to the industrial standards.

\section{Acknowledgments}

The authors are thankful to the support for Coordination for the Improvement of Higher Education Personal - Brazil (CAPES) - Finance Code 001. The author LBB Tavares is fellowship holder of the National Council for Scientific Technological Development - CNPq (Grant n.305880/2020-9). This study was financed in part by the Coordenação de Aperfeiçoamento de Pessoal de Nível Superior - Brasil (CAPES) - Finance code 001, received support of the Fundação de Amparo à Pesquisa e Inovação do Estado de Santa Catarina (FAPESC), and of the Universidade Regional de Blumenau (FURB).

\section{References}

Agnhage, T. Perwuelz, A. Behary, N. Eco-innovative coloration and surface modification of woven polyester fabric using bio-based materials and plasma technology. Industrial Crops and Products. (2016)

Bareth, A. Strohmar, W. Kitzelmann, E. HPLC and spectrophotometric
2.68

Easily distinguishable

determination of annatto in cheese. European Food Research and Technology. v. 215. n. 1. p. 359-364. (2002).

Bechtold, T. Mussak, R. Handbook of Natural Colorants. (2009).

Buchelt, B. Wagenführ, A. Evaluation of colour differences on wood surfaces. European Journal of Wood and Wood Products. v. 70. n. 1-3. p. 389-391. (2012).

Bueno, A. M. Gonçalves, M. J. Barcellos, I. O. Souza, C. K. Carvalho, L. F. Ibsch, R. B. M. Warmling, B. R. Bertoli, S. L. Colorimetric Analysis of the Stability of Annatto Dye in Solution and Its Use in the Dyeing of Polyester Fibers. Fibers and Polymers. v. 21. n. 1. p. 1-6. (2020).

Bunfueang, P. Samosorn, S. Bremner, J. B. Sajomsang, W. Gonil, P. Saisara, A. Chairat, M. Additive effects on cotton dyeing with dye extract from achiote seeds. Indian Journal of Fibre and Textile Research. v. 44. n. 4. p. 466-474. (2019).

Chan-Bacab, M. J. Sanmartín, P. Camacho-Chab, J. C. Palomo-Ascanio, K. B. Huitz-Quimé, H. E. Ortega-Morales, B. O. Characterization and dyeing potential of colorant-bearing plants of the Mayan area in Yucatan Peninsula, Mexico. Journal of Cleaner Production. (2015).

Chiarello, L. M. Mittersteiner, M. Jesus, P. C. Andreaus, J. Barcellos, I. O. Reuse of enzymatically treated reactive dyeing baths: Evaluation of the number of reuse cycles. Journal of Cleaner Production. (2020).

Chicatto, J. A. Rainert, K. T. Gonçalves, M. J. Helm, C. V. Altmajer-Vaz, D. Tavares, L. B. B. Decolorization of textile industry wastewater in solid state fermentation with peach-palm (Bactris gasipaes) residue. Brazilian Journal of Biology. (2018a).

Chicatto, J. A. Nunes, H. C. A. Gonçalves, M. J. Helm, C. V. Altmajer Vaz, D. Tavares, L. B. B. Strategies for decolorization of textile industry effluents by white-rot-fungi with peach palm residue. Acta Scientiarum Technology. (2018b).

Chicatto, J. A. Gonçalves, M. J. Altmajer-Vaz, D. Tavares, L. B. B. Treatment of the textile wastewater through fungi: a sustainable alternative. Sustentabilidade em Debate. v. 9. n. 1. p. 198-213. (2018c).

Criado, S. P. Gonçalves, M. J. Tavares, L. B. B. Bertoli, S. L. Optimization of electrocoagulation process for disperse and reactive dyes using the response surface method with reuse application. Journal of Cleaner Production. v. 275. n. 1. p. 122690. (2020).

Da Costa, C. L. S. Chaves, M. H. Extração de pigmentos das sementes de Bixa orellana L.: Uma alternativa para disciplinas experimentais de química orgânica. Quimica Nova. v. 28. n. 1. p. 149-152. (2005).

Gonçalves, M. J. Barcellos, I. O. Valle, R. C. S. C. Tavares, L. B. B. Estudo Da Viabilidade Do Tingimento Da Poliamida Com Corante Natural De Urucum. Revista Gestão \& Sustentabilidade Ambiental. (2020).

Hao, S. Chen, Q. Zhao, T. Dyeing Properties of Polyoxymethylene Fibers with Disperse Dyes. Fibers and Polymers. v. 20. n. 7. p. 1436-1442. (2019).

ISO, (International Organization for Standardization). ISO 105-X12:2016 Textiles - Tests for colour fastness - Part X12: Colour fastness to rubbing. (2016).

ISO, (International Organization for Standardization). ISO Textiles - test for color fastness - part C06: Colour Fastness to Domestic and Commercial Laundering. (2010).

Lellis, B. Fávaro-Polonio, C. Z. Pamphile, J. A. POLONIO, J. C. Effects of textile 
dyes on health and the environment and bioremediation potential of living organisms. Biotechnology Research and Innovation. v. 3. n. 2. p 275-290. (2019).

Lucarini, A. C. Tabu, A. S. F. Z. Silva, F. F. R. Moraes, G. A. Piazon, G. I. Zurawski, M. P. Estudo Da Extração De Corante Natural Que Confere Proteção Ultravioleta Em Fibras Naturais. The Journal of Engineering and Exact Sciences. v. 3. n. 2. p. 082-094. (2017).

Mahreni, Reningtyas, R. Priambudi, R. A. Sugiarti, F. I. Extract of Centella asiatica leaves as a biomordant in cotton dyed with natural dye Bixa orellana. Anais AIP Conference Proceedings. (2019).

Mercadante, A. Z. Steck, A. Pfander, H. Isolation and Identification of New Apocarotenoids from Annatto (Bixa orellana) Seeds. Journal of Agricultural and Food Chemistry. v. 45. n. 5. p. 1050-1054. (1997).

Mittersteiner, M. Schmitz, F. Barcellos, I. O. Reuse of dye-colored water posttreated with industrial waste: Its adsorption kinetics and evaluation of method efficiency in cotton fabric dyeing. Journal of Water Process Engineering. (2017).

Nakpathom, M. Somboon, B. Narumol, N. Mongkholrattanasit, R. High temperature dyeing of PET fabric with natural colourants extracted from annatto seeds. Pigment and Resin Technology. v. 48. n. 2. p. 129-136 (2019).

Nathan, V. K. Rani, M. E. Rathinasamy, G. Dhiraviam, K. N. Antioxidant and Antimicrobial Potential of Natural Colouring Pigment Derived from Bixa orellana L. Seed Aril. Proceedings of the National Academy of Sciences India Section B - Biological Sciences. v. 89. n. 1. p. 137-143. (2019).

Preston, H. D. and Rickard, M. D. Extraction and chemistry of annatto. Food Chemistry. v. 5. n. 1. (1980).

Petris, A. Gonçalves, M. J. Roratto, P. A. Goulart, J. A. G. Physicochemical, microbiological and parasitological characterization of the filter backwash water from a water treatment plant of Blumenau - SC and alternatives for treatment and reuse. Ambiente e Agua - An Interdisciplinary Journal of Applied Science. v. 14. n. 3. (2019).
Rainert, K. T. Nunes, H. C. A. Gonçalves, M. J. Helm, C. V. Tavares, L. B. B. Decolorization of the synthetic dye Remazol Brilliant Blue Reactive (RBBR) by Ganoderma lucidum on bio-Adsorbent of the solid bleached sulfate paperboard coated with polyethylene terephthalate. Journal of Environmental Chemical Engineering. v. 9. n. 2. 2021.

Rainert, K. T. Nunes, H. C. A. Gonçalves, M. J. Tavares, L. B. B. Equilibrium, kinetic and thermodynamic studies on the removal of reactive dye rbbr using discarded SBS paperboard coated with PET as an adsorbent. Desalination and Water Treatment. v. 86. p. 203-212. (2017).

Samanta, P. A Review on Application of Natural Dyes on Textile Fabrics and Its Revival Strategy. Chemistry And Technology Of Natural And Synthetic Dyes And Pigments. IntechOpen. (2020).

Shahid-Ul-Islam. Luqman, J. R. Mohammad, F. Phytochemistry, biological activities and potential of annatto in natural colorant production for industrial applications - A review. Journal of Advanced Research. v. 7. $n$. 3. p. 499-514. (2016).

Shahid, M. Shahid-UI-Islam. Mohammad, F. Recent advancements in natural dye applications: A review. Journal of Cleaner Production. v. 53. n. 15. p. 310-331. (2013).

Singh, H. B. Bharati, K. A. Handbook of Natural Dyes and Pigments. Elsevier (2014).

Tocchini, L. Mercadante, A. Z. Extração E Determinação, Por Clae, De Bixina E Norbixina Em Coloríficos. Ciência e Tecnologia de Alimentos. v. 21. n. 3. p. 310-313. (2001).

Zaman, N. U. Liman, M. L. R. Kader, A. Mamun, M. A. A. Sarker, B. Islam, R. Parveen, I. An Eco-friendly Approach of Cotton Fabric Dyeing with Natural Dye Extracted from Bixa orellana Seeds Employing Different Metallic Mordants. Chemical and Materials Engineering. v. 6. n. 1. p. 1-8. (2018) 